ARTIGO

\title{
FORMAÇÃO DOCENTE E AS RELAÇÕES DE GÊNERO E SEXUALIDADE NO CURSO DE PEDAGOGIA
}

\author{
TEACHING TRAINING AND THE RELATIONSHIPS OF GENDER AND SEXUALITY \\ IN THE PEDAGOGY COURSE
}

\author{
LA FORMACIÓN DE PROFESORES Y LAS RELACIONES DE GÉNERO Y \\ SEXUALIDAD EN EL CURSO DE PEDAGOGÍA
}

Nilson Sousa Cirqueira

Universidade Estadual do Sudoeste da Bahia - Brasil

José Valdir Jesus de Santana

Universidade Estadual do Sudoeste da Bahia - Brasil

Reginaldo Santos Pereira

Universidade Estadual do Sudoeste da Bahia - Brasil

\begin{abstract}
Resumo: Este artigo é um recorte de uma pesquisa de mestrado realizada em um curso de Pedagogia da Universidade Estadual do Sudoeste da Bahia (UESB), campus de Itapetinga-BA, no ano de 2019. A pesquisa teve como objetivo problematizar os discursos sobre gênero e docência a partir dos enunciados dos (as) discentes e docentes do referido curso. Como referencial teórico foram utilizados os estudos de Reis (2011), Ferreira (2013a), Hampel (2013), Castro (2014), Sales (2016), Silva (2017), Meyer (2017), Felipe e Takara (2020), dentre outros. Como técnicas de produção dos discursos foram utilizadas a entrevista semiestruturada e o grupo focal com 6 (seis) docentes (1 homem e 5 mulheres) e 10 (dez) discentes ( 8 mulheres e 2 homens). As perspectivas que organizam as análises amparam-se nos estudos pós-críticos das relações de gênero, sexualidade e educação. A partir das análises realizadas, constatamos que o curso de Pedagogia tem problematizado as relações de gênero e sexualidade na formação docente, no entanto, os discursos evidenciam que ainda há lacunas quando se trata dessas temáticas no currículo do curso. Além disso, os enunciados mostram que o curso não tem trabalhado de forma interdisciplinar ao tratar dos conteúdos sobre gênero e sexualidade. A investigação também revelou que discentes e docentes acenam para a necessidade de mudanças e manifestam algumas alternativas para alterar esse cenário, dentre elas, o atravessamento dessas discussões por todas as disciplinas que fazem parte da matriz curricular.
\end{abstract}

Palavras-chave: Currículo. Docência. Gênero. Sexualidade.

Abstract: This article is an cut from a master's research conducted in a Pedagogy course at the State University of Southwest Bahia (UESB), campus of Itapetinga-BA, in 2019. The research aimed to problematize the discourses on gender and teaching based on the statements of the students and teachers of that course. As a theoretical framework, the studies of Reis (2011), Ferreira (2013a), Hampel (2013), 
Castro (2014), Sales (2016), Silva (2017), Meyer (2017), Felipe and Takara (2020), were used, among others. As techniques of discourse production, semi-structured interviews and the focus group with 6 (six) teachers ( 1 man and 5 women) and 10 (ten) students ( 8 women and 2 men) were used. The perspectives that organize the analyzes are supported by post-critical studies of gender relations, sexuality and education. From the analyzes carried out, we found that the Pedagogy course has problematized gender and sexuality relations in teacher education, however, the speeches show that there are still gaps when it comes to these themes in the course curriculum. In addition, the statements show that the course has not worked in an interdisciplinary way when dealing with content on gender and sexuality. The investigation also revealed that students and professors point to the need for changes and manifest some alternatives to change this scenario, among them, the crossing of these discussions by all the disciplines that are part of the curriculum.

Keywords: Curriculum. Teaching. Gender. Sexuality.

Resumen: Este artículo es un extracto de una investigación de maestría realizada en un curso de Pedagogía en la Universidad Estatal del Sudoeste de Bahía (UESB), campus de Itapetinga-BA, en 2019. La investigación tuvo como objetivo problematizar los discursos sobre género y docencia a partir de las declaraciones de los alumnos y profesores de ese curso. Como referencial teórico foram utilizados los estudios de Reis (2011), Ferreira (2013a), Hampel (2013), Castro (2014), Sales (2016), Silva (2017), Meyer (2017), Felipe e Takara (2020), entre otros. Como técnicas de producción de discurso se utilizaron entrevistas semiestructuradas y el grupo focal con 6 (seis) profesores ( 1 hombre y 5 mujeres) y 10 (diez) estudiantes ( 8 mujeres y 2 hombres). Las perspectivas que organizan los análisis se apoyan en estudios poscríticos sobre relaciones de género, sexualidad y educación. A partir de los análisis realizados, encontramos que el curso de Pedagogía ha problematizado las relaciones de género y sexualidad en la formación del profesorado, sin embargo, los discursos muestran que aún existen vacíos en estos temas en el currículo del curso. Además, los enunciados evidencian que el curso no ha funcionado de manera interdisciplinar cuando se trata de contenidos sobre género y sexualidad. La investigación también reveló que estudiantes y profesores señalan la necesidad de cambios y manifiestan algunas alternativas para cambiar este escenario, entre ellas, el cruce de estas discusiones por todas las disciplinas que forman parte del currículo.

Palabras clave: Currículum. Docencia. Género. Sexualidad.

\section{Introdução}

A dificuldade e a pluralidade das atribuições e demandas sobre a formação docente talvez seja no contexto atual um dos assuntos mais sensíveis aos olhos dos (as) educadores (as). Em um contexto de intensos debates na esfera educacional, uma das reclamações que ganham destaque refere-se ao despreparo que muitos (as) professores (as) têm na hora de discutir assuntos que envolvem gênero e sexualidade na sua prática pedagógica. Falar sobre essas temáticas na sociedade não tem sido muito fácil devido a algumas “verdades” já cristalizadas e propagadas pela sociedade, desmerecendo os estudos que tratam dessas questões.

Os estudos de Reis (2011), Ferreira (2013a), Hampel (2013), Castro (2014), Sales (2016), Silva (2017) e Meyer (2017) demonstram o quanto têm sido difícil o debate acerca das 
relações de gênero e sexualidade na formação docente pelo país. Os (as) autores (as) relatam que muitos dos cursos de formação docente não têm problematizado essas temáticas e dado a devida atenção a esses conhecimentos no processo formativo dos (as) seus (as) formandos (as). Existem instituições que sequer possuem disciplinas que discutem esses conteúdos nos seus currículos.

Sabemos que os cursos de formação docente não têm como preparar esses sujeitos em toda a sua estrutura para estarem discutindo essas temáticas, no entanto, há de se pensar que mesmo os cursos não tendo condições de preparar esses indivíduos (é necessário que dê continuidade na formação continuada) para trabalharem com esses temas na sua prática pedagógica caso queiram seguir a carreira docente, isso não isenta as instituições dos debates necessários nos seus currículos.

Tendo contato com o cotidiano escolar, muitas vezes nós percebemos as dificuldades, dúvidas dos (as) docentes quando precisam debater e lidar com perguntas desconcertantes e/ou com conflitos entre os (as) discentes que decorrem de diferentes motivos, inclusive referentes a gênero e sexualidade. Muitos (as) desses (as) profissionais que estão na sala de aula não tiveram acesso a essas temáticas na sua formação, o que acaba agravando o debate na sua prática pedagógica. Há de se lembrar que existe também resistência por parte de docentes mais conservadores (as) em discutir esses assuntos devido aos seus valores morais e religiosos que agravam ainda mais a situação.

Muitos (as) deles (as) se sentem "constrangidas (os) em abordar esses conteúdos, preferindo, muitas vezes, 'fechar os olhos' para situações que conduzam à abordagem desse tipo de assunto" (REIS, 2011, p. 97). Esses temas ainda continuam avançando, e constituindose, de certa maneira, como "pontos cegos" que induzem professores (as), gestores (as) a reforçar "enfaticamente, em muitos dos processos formativos [...], ou que essas coisas 'são normais"”, "sempre foram assim" ou, em maior número, que "não estamos preparados para lidar com essas questões" (MEYER; DORNELLES, 2013, p. 43).

Muitos (as) profissionais, pesquisadores (as) da área da educação têm questionado acerca desse despreparo. Será que os cursos de formação de professores (as) têm debatido, problematizado esses temas nos seus currículos? Que discursos e enunciados sobre gênero e sexualidade circulam no currículo e como formam esses sujeitos? Essas questões perpassam por todas as outras disciplinas do curso? São temas que merecem ser debatidos, porque a formação docente possui uma dimensão de alta complexidade não somente por sua natureza, "pois formar é algo complexo, envolve tanto a dimensão de quem forma, o/a professor/a formador/a, como a de quem é formado, o/a professor/a em formação" (REIS, 2011, p. 89). 
Conforme Castro (2014), quando falamos em formação docente para as relações de gênero e sexualidade é importante considerar também que ela está imersa em redes de poder, cujas tramas envolvem conflitos, tensões, negociações, nesse aspecto, quando se trata da inserção dessas temáticas no campo educacional como na formação de professores (as) os avanços nessa direção confrontam-se com a resistência de discursos decorrentes das instâncias conservadoras. "[...] Os grupos conservadores têm atuado diretamente no sentido de coibir a abordagem dessas temáticas nos materiais didáticos, nas formações e nas práticas docentes" (OLIVEIRA; OLIVEIRA, 2018b, p. 17). Existem projetos tanto no âmbito nacional, estadual e municipal que têm como principal intuito proibir "a discussão de gênero e sexualidade no espaço escolar" (FELIPE; TAKARA, 2020, p. 139).

Essas resistências, segundo Foucault (1996; 1986), funcionam como relações de poder, são elementos do exercício do poder que são acionados para interditar certas palavras, conteúdos, assuntos, modos de falar sobre certas temáticas e práticas. Essas relações de poder estão inscritas no currículo por meio das divisões entre os saberes que são inerentes ao processo de seleção de determinados conhecimentos, pois, como nos lembra Silva (2017), aquilo que divide tanto pode incluir como excluir e isso é poder, aquilo que "divide o currículo - que diz o que é conhecimento e o que não é - e aquilo que essa divisão divide - que estabelece desigualdades entre indivíduos e grupos sociais - isso é precisamente o poder" (SILVA, 2013, p. 191) e esse poder ganha forma através dos discursos conservadores que têm dificultado o debate sobre gênero e sexualidade nos currículos escolares e na formação docente nas instituições em todo o país.

Assim, esse artigo vem problematizar algumas questões apresentadas acima e, para isso, tomamos como base os discursos e enunciados proferidos por docentes e discentes do curso de Pedagogia - campus de Itapetinga-Bahia, os quais vivenciaram/vivenciam esses dilemas na sua práxis pedagógica e no seu processo formativo.

A pesquisa foi realizada no curso de Pedagogia da Universidade Estadual do Sudoeste da Bahia (UESB), campus de Itapetinga-Ba no ano de 2019. A metodologia aplicada foi de abordagem qualitativa a partir dos referenciais teóricos dos estudos pós-críticos de gênero e sexualidade. Em relação às técnicas utilizadas para a produção dos dados, optamos pela entrevista semiestruturada e o grupo focal. Participaram da pesquisa 6 (seis) docentes (1 homem e 5 mulheres) e 10 (dez) discentes (8 mulheres e 2 homens) do curso de Licenciatura em Pedagogia. O critério utilizado para a seleção dos (as) docentes levou em consideração as disciplinas ministradas, especialmente aquelas que tivessem maior proximidade com a educação da pequena infância, além das disciplinas de Currículo e Educação, Gênero e 
Sexualidade. Já em relação aos (as) discentes, foram escolhidos aqueles (as) que estavam em processo de conclusão de curso, o oitavo semestre. O método utilizado para a análise foi a Análise do discurso (AD) numa perspectiva foucaultiana.

\section{Discursos dos (as) docentes e discentes sobre gênero e sexualidades no curso de Pedagogia}

O discurso tem o poder de deixar marcas, é produtor de identidades, de lugares e de "verdades". Ele é o responsável por dá mobilidade ao conhecimento que nos constitui como sujeitos (FOUCAULT, 1986). Assim, propomos aqui apresentar algumas "verdades" enunciadas por discentes e docentes acerca da discussão de gênero e sexualidadade no curso de Pedagogia.

Muitos cursos de formação docente não têm oferecido disciplinas nos seus currículos que tratem sobre os temas de gênero e sexualidade na formação de seus (suas) formandos (as). Sobre essa questão, consideramos positivo que o curso de Pedagogia da UESB - campus de Itapetinga-BA possui uma disciplina na sua estrutura curricular que discute a temática de gênero e sexualidade intitulada "Educação, Gênero e Sexualidade", com caráter obrigatório de 60 horas ( 3 créditos - 2 teóricos e 1 prático), e atualmente está alocada no $5^{\circ}$ período do curso, oferecida semestralmente. No entanto, como veremos nos discursos dos (as) discentes e docentes, mesmo o curso tendo a disciplina, ainda assim, existe uma deficiência no que tange às discussões de gênero e sexualidade no curso e na instituição como um todo.

"A gente tem [...] no curso a disciplina, mas, esses assuntos precisam estarem presentes em todas as disciplinas. Discutir gênero, docência, Pedagogia, sexualidade, enfim, essas questões não podem ser em uma disciplina pontual, uma disciplina pontual geralmente é um estanque, ela é uma disciplina de 60, 75 horas [...] elas não podem ser isoladas e terminar com um fim em si mesma, elas precisam serem discutidas em todos os espaços. [...] Então, eu penso que ela precisa perpassar por todas as disciplinas do currículo" (NILTON $1 /$ docente).

"Eu acho que deveria perpassar por todas as disciplinas [...] é um questionamento que eu sempre coloco. [...] Deveriam passar por todas as disciplinas, por que só numa disciplina específica? [...] Então, eu acho que você acaba ficando ... deixando esses assuntos específicos para uma coisa que está ligada com todas as outras" [...] (ESTER/discente).

\footnotetext{
${ }^{1}$ Considerando as questões éticas da pesquisa utilizamos nomes fictícios para preservar a identidade dos participantes.
} 
O que podemos observar nos enunciados é que por mais que exista a disciplina específica no curso e que trate especificamente sobre gênero e sexualidade a discussão não pode se limitar somente a ela, posto que esse debate tem que ser contextualizado, interdisciplinar, perpassado em outras disciplinas do currículo e, segundo Castro (2014), o desejável seria que houvesse um "atravessamento dessas discussões em todas as disciplinas [...]" (p. 78). Deveria existir uma integração entre elas, assim, o debate sobre gênero e sexualidade ganharia corpo e importância e seria mais produtivo. Comungando com os argumentos do docente Nilton e da discente Ester, a docente Aura e os (as) discentes Carla e Jaime afirmam que:

“[...] É um trabalho que você faz em todas as disciplinas [...]. Então, eu acho que as disciplinas em si em um momento ou outro elas têm situações, tem conteúdo que dar para você fazer esse trabalho, porque não tem como você considerar, ah, só nessa disciplina você vai trabalhar isso [...]" (AURA/docente).

"[...] A gente tem mais três cursos de licenciatura que não é discutido, e não tem na sua matriz curricular gênero, sexualidade e educação, eles vão para escola de fundamental II aqui, e vão para o ensino médio, eles vão lidar, principalmente, com essa fase em que eu preciso dialogar com esses alunos isso [...]. Então, na minha concepção eles deveriam ser dialogados em toda a universidade" (CARLA/discente).

“....] Essas temáticas deveriam perpassar por todo o curso, sua grade curricular deveria ter essas questões a serem discutidas e penso além disso, a gente no âmbito da universidade esses temas deveriam ser discutidos em outras áreas também como nas exatas, deveria ser ampliado" [...] (JAIME/discente).

De fato, não há como se restringir o conhecimento apenas a uma disciplina, pois ele transita por todos os espaços, uma hora ou outra os (as) docentes passarão por alguma experiência na sua prática pedagógica que possa envolver essas questões com os seus (as) educandos (as). Além do mais, concentrar essas temáticas apenas a uma matéria curricular impede que os (as) educandos (as) compreendam gênero e sexualidades por outros pontos de vista, afinal, "tanto gênero como a sexualidade são entendidos como produzidos discursivamente [...]” (PARAÍSO, 2018, p. 215). É como a docente Camila diz: “as características deles/as relacionadas a gênero e sexualidade vão ser manifestadas em todos os momentos, em todas as disciplinas, em qualquer curso que elelela tiver”.

Gênero e sexualidade estão em todo lugar, são elementos que nos constituem como sujeitos, não há como nos desprendermos deles. "Isso nos permite afirmar que instituições como a escola, a mídia, a justiça, a igreja, etc., são generificadas e sexualizadas, ou seja, são constituídas por e constituintes dos gêneros e das sexualidades” (FURLANI, 2005, p. 230. 
Grifos da autora). Ainda em relação aos enunciados, principalmente, dos (as) discentes Carla e Jaime, nos chamaram a atenção os seguintes fragmentos:

"[...] A gente tem mais três cursos de licenciatura que não é discutido, e não tem na sua matriz curricular gênero, sexualidade e educação[...]" (CARLA/discente).

"[...] No âmbito da universidade esses temas deveriam ser discutidos em outras áreas [...] como nas exatas, deveria ser ampliado" (JAIME/discente).

Esses discursos nos fazem refletir em relação a processos de consolidação dos debates sobre gênero e sexualidade que transcendem as relações internas do curso de Pedagogia e nos convida a pensar sobre outros agentes, outros formatos que ultrapassem os limites da sala de aula e do curso. Já que existem, no campus de Itapetinga mais cursos de licenciatura, como Química, Física e Biologia e os sujeitos que se graduarem neles também serão professores, seria importante que também tomassem conhecimento dessas discussões no seu processo formativo, afinal, seu campo de atuação será a sala de aula e, consequentemente, passarão por algumas situações que envolverão a temática de gênero e sexualidade na sua práxis pedagógica.

Discentes e docentes também elucidaram que apenas a disciplina por si só não abarca todo o conteúdo que existe acerca dos estudos de gênero e sexualidade no curso. Para os (as) docentes Nilton, Camila e a discente Carla,

"[...] A disciplina não dá conta, eu acho que é um tema muito amplo para se discutir numa disciplina durante um semestre, eu não conheço o plano de trabalho dessa disciplina, mas, eu acredito que tragam temas assim que fundamentais e que dão margens para os alunos buscarem mais. $\dot{E}$ uma disciplina necessária, porém, muito curta para poder discutir todos os temas, então, eu penso que ela não alcança o seu propósito exatamente pela insuficiência de tempo e das discussões que acabam sendo limitadas apenas num período letivo" (NILTON/docente).

"[...] Eu creio que a disciplina em si não dá conta de uma formação de um sujeito. O sujeito está em constante transformação, o sujeito é mutável, uma disciplina em si que você passa ali 60 horas com uma pessoa discutindo relações de gênero não vai lhe abarcar toda a sua vivência enquanto sujeito (CAMILA/docente)".

"[...] Deveria ter gênero e sexualidade I, II e III, porque uma disciplina só é muito pouco para você discutir [...]. Se a gente for pensar que estamos formando educadores para o Brasil, para atuar na educação básica, eu acho as discussões rasas e, ... eu atrevo a dizer, que são discussões rasas e pouco problematizadas" (CARLA/discente). 
Nesses relatos notamos que tanto docentes como a discente concordam que existe uma insuficiência da discussão da temática no curso, pois, segundo afirmam, são temas amplos e apenas uma disciplina ofertada semestralmente não consegue abarcar assuntos tão relevantes para a formação dos (as) pedagogos (as). É “uma temática muito ampla, então, é difícil de você ater só àquela disciplina, porque é muito grande e discussão vasta” (GISELE/discente).

Nós percebemos que não há tempo hábil para uma discussão mais aprofundada, teórica sobre as temáticas, levando aqueles (as) que se interessam pela temática a recorrerem a outros meios para adquirirem mais conhecimentos e aprofundarem no assunto, é o caso da discente Aleuda: “as discussões são poucas porque se limita muito a uma disciplina só. Então, você acaba lendo, vendo vídeos, entrevistas sobre o caso, então, você acaba se aprofundando mais nessas leituras". Outra solução que os (as) discentes encontram para ficarem mais próximos do debate acerca de gênero e sexualidade é se aproximar de docentes que discutem a temática, assim, acabam produzindo artigos, trabalhos de conclusão de curso e participando de eventos científicos. Sobre isso, a discente Talita narra que: "[...] no caso específico aqui da gente que participa dos eventos da Pedagogia além da universidade, a gente tem muita discussão, mas quem não tem a oportunidade de participar é complicado”.

Ao analisar a fala da discente, entendemos que o debate sobre gênero e sexualidade, especificamente no campus de Itapetinga-BA é um pouco deficiente. Quando a discente diz que aqueles (as) que participam dos eventos da Pedagogia, que possivelmente são em outros estados e em outras universidades da região, eles (as) acabam tendo mais acesso à discussão sobre a temática, porém quem não têm essa oportunidade por vários motivos, como trabalho, família, condição financeira, acabam sendo prejudicados (as) quanto ao acesso às temáticas de uma forma mais ampliada, para além da disciplina. Acerca disso, a discente Denise elucida que os (as) discentes que não têm a oportunidade de viajar para os encontros da Pedagogia acabam estudando "as temáticas de forma fragmentada. [...] A gente tem que montar esse quebracabeças para sair com alguma coisa”. Em relação ao argumento da colega, a discente Ester esclarece o seguinte:

"[...] Eu acho que deveria ter discutido gênero, sexualidade, depois os dois mais educação, porque são coisas que têm uma história, como foi que surgiu? Então, não dá tempo de fazer essa parte histórica, depois fazer essa relação com a educação, metodologias, como agir, e é algo muito polêmico esse assunto [...]" (ESTER/discente).

Observando o enunciado da discente até que seria uma boa opção para o debate das temáticas de gênero e sexualidade, mas como pesquisadores da temática entendemos que não 
existe viabilidade em uma única disciplina curricular fazer todo esse percurso histórico do surgimento do conceito de gênero e sexualidade e sua aplicabilidade na educação, pois "não há formação, não há currículo e, sobretudo, não existem docentes que deem conta de tudo isso" (MEYER, 2017, p. 65).

Para Hampel (2013), essas temáticas estarem presentes "no currículo não garante, necessariamente, que a abordagem implementada para tais discussões contemple aspectos históricos, sociais e culturais" (p. 127) que assegurariam alterações positivas no processo formativo dos (as) licenciandos (as), isso envolve o processo de formação continuada, daí a importância dos cursos de formação docente proporcionarem uma formação inicial e continuada mais ampla, para, assim, permitir que os (as) discentes pensem gênero e sexualidade em toda a sua complexidade. Diante disso, as docentes Josi e Edna relatam:

\begin{abstract}
"Eu acredito que a formação [...] ela tem um viés da formação inicial e da continuada, então, aqui na graduação é a formação inicial, então os temas, conteúdos, enfim, é discutido numa perspectiva da formação inicial. Mas é necessário que se faz a questão da formação continuada. [...] A formação continuada numa perspectiva de pós-graduação, em cursos de especialização, mestrado e doutorado, [...] ] gente não pode dizer não, já sei tudo sobre isso, ou tal curso deu conta de formar o graduando para essa discussão [...]" (JOSI/docente).
\end{abstract}

"[...] Eu penso que a formação inicial que é no caso essa aqui, essa formação não é o suficiente para estar lá na educação e dizer assim, eu tenho uma boa formação. Eu penso que há a necessidade de uma formação continuada [...]. Então, eu acho que a formação inicial ela prepara, ela dar uma boa base, uma preparação para ele estar atuando, mas, falta continuidade, a formação continuada, porque isso é o dia a dia, é o bate e volta [...]" (EDNA/docente).

Uma das formas de dar continuidade à formação docente após a formação inicial relatada pelas docentes é realmente a formação continuada. Porém, temos que entender que nem todos (as) têm essa oportunidade de estar realizando um curso lato ou stricto sensu tão bem lembrado pela docente Josi, principalmente, aqueles (as) docentes que já estão na sala de aula.

O que se observa é que são muitos os desafios quando pensamos no aumento da formação inicial e continuada para os (as) nossos (as) profissionais, pois, como nos relata Oliveira e Maués (2012), a falta de tempo, os baixos salários dos (as) professores (as), a pouca oferta de cursos, a desarticulação da oferta com os órgãos educacionais (MEC, Secretarias de Educação, Instituições Universitárias) com os problemas e necessidades das escolas, a desarticulação das instituições formativas com as secretarias de educação, a necessidade de 
planejamento colegiado, agilidade, incentivos, monitoramento das ações de formação, dentre outras, dificultam ainda mais essa formação.

Outro discurso observado nas falas dos (as) discentes e docentes foi sobre o posicionamento e a falta de conhecimento de alguns (mas) docentes relacionados à discussão sobre gênero e sexualidade no curso de Pedagogia.

\section{"[...] Tem [...] professores no curso que se furtam a fazer esse debate em torno de gênero e sexualidade [...] tem o próprio preconceito, sendo que a gente está dentro de um local que é para produzir o conhecimento, é para discutir todos os assuntos" [...] (JAIME/discente).}

Às vezes os professores também não tem esse conhecimento e os formandos saem daqui sem ter nem o que falar quando chega lá na sociedade e são questionados sobre as questões de gênero e sexualidade, e aí como que esse professor ele [...] vai fazer algo diferente se nem ele mesmo tem esse conhecimento, essa problematização toda?" (ESTER/docente).

Infelizmente as instituições de ensino superior não estão livres de terem no seu corpo docente profissionais que não querem se envolver com as questões de gênero e sexualidade e não estão preparados para debaterem esses assuntos na sua prática pedagógica, essa realidade não é restrita somente à educação básica. Muitos (as) docentes se mostram resistentes e despreparados (as) acerca dessas temáticas, na maioria das vezes eles (as) "omitem questionamentos, disfarçam curiosidades e inquietações, muitas vezes, por medo de se exporem ou porque tudo isso é contrário a tudo que aprenderam" (SILVA, 2017, p. 37).

Em um contexto de abertura, após longas batalhas para que as temáticas de gênero e sexualidade vistos como "marginais" viessem a ser teorizados nos currículos educacionais, dando espaço para novos discursos, novas experiências, novos conhecimentos, é um tanto desanimador que ainda convivamos com discursos conservadores que buscam limitar e restringir a abordagem desses conteúdos (SALES, 2016).

É por ações como essas que, segundo o docente Nilton, o curso "tem formado profissionais homofóbicos, machistas, misóginos, racistas, exatamente por isso, por essa visão estrita e pontual, não da disciplina, mas da forma com que eles aprendem na disciplina [...]”. Portanto, temos que ter o cuidado de como nos posicionamos acerca de determinados conhecimentos, temos que começar a identificar na nossa prática diária como educadores (as) as características dos nossos próprios discursos e de nossas práticas particulares que podem ter efeitos negativos, dominadores. "Temos que questionar a 'verdade' de nossos próprios e cultivados discursos, examinar aquilo que faz com que sejamos o que somos" (GORE, 2010, p. 
17), para não corrermos o risco de estarmos sendo preconceituosos (as) com certos sujeitos e seus saberes.

Segundo Meyer (2017, p. 74), é preciso que nós nos abramos “para aquelas coisas que, até então, não nos permitíamos sequer pensar ou imaginar” (MEYER, 2017, p. 74). É preciso valorizar o como se discute sobre "gênero ou sexualidade, abordar a diversidade de gênero fora da camisa de força da heteronormatividade” (SOUZA; MIRANDA, 2013, p. 127).

\section{Os estudos de gênero e a interdisciplinaridade no curso de Pedagogia}

Encontramos também nos discursos dos sujeitos a questão da interdisciplinaridade. Fazenda (2008) nos lembra que a interdisciplinaridade é um processo de interação e trocas, é uma integração de pensares, ditos e feitos que é organizada no âmbito das disciplinas. Assim, é fundamental que haja uma articulação entre os saberes disciplinares. Na pesquisa, os sujeitos também revelaram que os temas sobre gênero e sexualidade deveriam perpassar por todas as disciplinas, no sentido de construir um trabalho interdisciplinar.

"[...] Quando a gente fala de um currículo interdisciplinar [...] a gente sabe que ... Isso tem no nosso projeto de curso, o projeto curricular do curso de Pedagogia ele versa sobre uma proposta interdisciplinar. [...] Por exemplo, temos uma disciplina específica para gênero e sexualidade e específica para educação étnico-racial. Eu vejo que essa discussão se concentra nessas duas disciplinas [...]”" (EDNA/docente).

O que podemos verificar na fala da docente é que o Projeto Pedagógico do Curso de Pedagogia (PPC) aborda sobre o trabalho interdisciplinar. "O trabalho interdisciplinar deve prevalecer enquanto norteador da práxis docente" (UESB, 2010, p. 36). Todavia, o que se observa no enunciado é que mesmo a proposta interdisciplinar sendo parte fundante do Projeto Pedagógico do Curso de Pedagogia (PPC), ainda assim, não há na prática pedagógica da maioria dos (as) docentes essa ação, isso fica sob responsabilidade de alguns (mas) professores (as) que ficam a cargo das disciplinas que discutem as temáticas sobre educação e relação étnico-racial e as relações de gênero e sexualidade.

Com relação a isso, Castro (2014, p. 68) nos lembra que os lugares ocupados por professores (as) que discutem temas sobre gênero e sexualidade nas universidades acabam se tornando de um (a) determinada pessoa. Ademais, para o autor, "são raras as oportunidades de discussão em outras disciplinas no que tange às sexualidades, e mais raras ainda em se tratando das relações de gênero". Em consonância com o argumento da docente Edna, acima, os (as) discentes Jaime, Aleuda e Denise entendem que: 
"Aqui dentro da universidade a gente não trabalha essa interdisciplinaridade entre as matérias, entre os professores, entre alunos, a gente acaba que voltando para o tradicionalismo [...]. Eu acho que a universidade peca nesse sentido aí, então, eu acho que tem como ampliar esse campo com a participação de todos para alunos e professores independente do campo que ele se acha confortável, então o debate tem que ser ampliado a todos" (JAIME/discente).

"Eu acho que ela deveria ser mais ampla, quando eu falo mais ampla na questão do que eles falam muito da questão da interdisciplinaridade dentro das disciplinas [...]" (ALEUDA/discente).

"Às vezes o professor fica limitado naquela disciplina e não abre discussões para outras temáticas né? Não faz trabalho transversal voltados para essa temática que é importante, porque é uma coisa que a gente leva para o dia a dia né?" (DENISE/discente).

Ao nosso ver, talvez essa falta de integração, "ausência" interdisciplinar na práxis pedagógica, que podemos observar nos enunciados, deva ser por causa de uma má articulação entre os saberes disciplinares e uma forma errônea de se praticar o trabalho interdisciplinar que acaba caindo no tradicionalismo, como bem disse o discente Jaime. Nesta perspectiva, Santomé (1998, p. 1) argumenta que as instituições, quando se propõem a trabalhar de um modo interdisciplinar,

[...] Muitas vezes, para estar na moda ou cumprir a legalidade, muda-se apenas a aparência das propostas; no fundo, porém, continua se fazendo a mesma coisa. A rica filosofia de conceitos [...] pode acabar em mera rotina, em propostas técnicas, completamente alheias aos problemas que serviram de estímulo para sua formulação.

Então, ao tentar trabalhar nessa perspectiva, há que se compreender que a interdisciplinaridade não é apenas uma proposta meramente teórica, epistemológica, conceitual, mas, sobretudo, uma prática, ela não é uma justaposição de disciplinas, muito menos uma "prática de aniquilação", onde uma determinada matéria curricular se sobrepõe a outra, porém, uma "articulação necessária dos saberes docentes e disciplinares, numa postura metodológica transformadora capaz de inovar e construir novos conhecimentos a partir da integração e colaboração entre os diversos campos do conhecimento" (UESB, 2010, p. 38).

Nós observamos que os (as) discentes afirmam que não há um trabalho interdisciplinar no curso de Pedagogia e quando há acaba seguindo o velho tradicionalismo. Analisando os discursos dos (as) docentes, encontramos relatos de que há um trabalho ou pelo menos uma breve discussão acerca dessas temáticas em suas disciplinas.

"Então, na disciplina de estágio [...] eu sempre faço um estudo quando eu estou preparando para os alunos irem, eu distribuo textos em várias áreas da educação infantil que podem ser trabalhados [...]. Por exemplo, no último 
estágio que eu atuei eu distribuí o texto: o corpo fala, que fala sobre a sexualidade na infância, trabalhei um texto de educação étnico-racial na infância, então, tudo focado para primeira infância. Então, a partir desses textos, eles apresentam, eles leem, discutem, eles podem estar pensando em propostas de trabalho para atuar na educação infantil. Então, tem dupla, tem grupo que vai para questão racial, que vai para ... Agora, quase não tem trabalhos na questão sexual, na questão de gênero na educação infantil, assim, quando eles leem e discute há uma socialização ali do material, mas, de preparar o projeto há um foco muito mais na questão do ensino e aprendizagem no sentido da leitura e da escrita que propriamente discutir temáticas como essas [...]. Mas, abordamos as temáticas até porque a exemplo mesmo dessa diversidade que está no contexto da escola e como eles vão para o estágio eles precisam tomar conhecimento" (EDNA/docente).

"Na verdade, em currículo a gente trabalha com a questão de gênero e sexualidade dentro da teoria, dos movimentos sociais que vem colocando isso, dentre elas a própria teoria queer, que vem discutindo um pouco essa questão de gênero, na teoria feminista do currículo. [...] Então, a gente já trabalha isso dentro do próprio campo de discussão curricular" (LEDA/docente).

Como podemos verificar nas falas das docentes Edna e Leda, há uma discussão sobre gênero e sexualidade em suas disciplinas, enquanto em uma o debate é mais no sentido da prática, da ação dos (as) discentes com o estágio, através de projetos para serem trabalhados na regência, a outra é mais numa perspectiva teórica. Mas o que nos chama atenção são os fragmentos da fala da docente Edna: "[...] quase não tem trabalhos na questão sexual, na questão de gênero na educação infantil [...]”. “[...] Há um foco muito mais na questão do ensino e aprendizagem no sentido da leitura e da escrita que propriamente discutir temáticas como essas [...]".

Percebemos que os (as) discentes têm um certo receio, medo de trabalhar com temas que tenham relação com as temáticas de gênero e sexualidade, principalmente se for na educação infantil. Gênero e sexualidade ainda são conteúdos classificados como delicados, tabus no espaço escolar (WELTER; GRAUPE; GROSSI, 2018), considerados “marginais", e os discursos falsos, as estratégias de poder que tentam fiscalizar, controlar o currículo e que tem sido propagado em toda a sociedade têm contribuído para que as pessoas vejam gênero e sexualidade como temas não escolares (FELIPE; TAKARA, 2020; PARAÍSO, 2018). Um fato que narra toda essa preocupação em discutir gênero e sexualidade na educação, principalmente no ensino infantil, é o da docente Josi. Segundo ela um aluno teve algumas dificuldades quando ele foi realizar o estágio com um tema envolvendo gênero e sexualidade na educação infantil em certa escola no município de Itapetinga, o caso foi tão polêmico que foi preciso fazer até reunião com os pais dos alunos, vejamos: 
"[...] Tivemos que fazer uma reunião com os pais pra dizer que ele ia trabalhar com essas questões de gênero com as crianças. E... mas ao mesmo tempo nós conversamos com a diretora para não causar um rebuliço e isso provocar e até dificultar o trabalho dele [...]. O tempo todo ele ficou numa posição, assim, sendo observado pela coordenação, pela diretora, o tempo todo naquele melindre, de como que ele ia tratar a temática. Nós tivemos resultados positivos, o trabalho... claro que alguns ajustes inclusive eu precisei fazer no plano por conta mesmo para não criar um conflito com a comunidade escolar, com a diretora que veio muito apreensiva. [...] A gente percebeu logo uma diferença em relação à temática dele, de querer discutir isso, de fazer uma reunião com os pais para informar, inclusive, a diretora argumentou: é porque também ele é homem e aí pode ter um diferencial [...]" (JOSI/docente).

Essa situação pela qual o discente passou é bastante comum na nossa sociedade, o pânico moral ${ }^{2}$ que se alastrou por todo o país tem feito com que as pessoas tenham receio de que seus (as) filhos (as) tenham contato com as questões de gênero e sexualidade nas escolas. Para elas (es), esses conteúdos são ameaçadores à ordem e aos valores morais tradicionais. Por isso, que a docente disse que teve de fazer alguns ajustes no plano, pois, caso não se adequasse às normas da escola, o discente não poderia fazer o estágio.

Um fragmento da fala da docente que nos chamou a atenção foi: "[...]. O tempo todo ele ficou numa posição, assim, sendo observado pela coordenação, pela diretora, o tempo todo naquele melindre, de como que ele ia tratar a temática”. Casos iguais a esses são constantemente vivenciados por professores (as) na maioria das instituições pelo país, frequentemente, esses sujeitos são vigiados, de muitas formas "não cessa sua vigilância, posto que no imaginário social os instintos carregados pelo sexo masculino produzem homens potencialmente sujeitos à depravação [...]” (CIRQUEIRA; SANTANA; PEREIRA, 2018, p. 77). Notamos que as docentes têm abordado as questões de gênero nas suas disciplinas, mas será que está sendo suficiente? Se elas seguirem o mesmo caminho do docente Nilton podemos considerar que não.

“[...] Confesso que abordo pouco, [...] eu enquanto educador não consigo fazer algumas distinções em relação a gênero, talvez, nessa questão eu já tenha conseguido superar a ideia de que uma profissão ela não pode ser nem feminizada nem masculinizada, porque ela é uma profissão e que pode ser exercida por ambos os sexos, eu não vejo mais essa distinção. Por essa razão, eu tenho abordado pouco nas minhas aulas essa questão, agora, eu não deixo de fazer sempre essa discussão na abertura do semestre letivo, de quais são as origens do educador infantil [...]" (NILTON/docente).

\footnotetext{
${ }^{2} \mathrm{O}$ conceito de pânico moral permite lidar com processos sociais marcados pelo temor e pela pressão por mudança social. Este conceito se associa a outros de muitas áreas como desvio, crime, comportamento coletivo, problemas e movimentos sociais, pois permite esclarecer os contornos e as fronteiras morais da sociedade em que ocorrem. Sobretudo, eles demonstram que o grau de dissenso (ou diversidade) que é tolerado socialmente tem limites em constante reavaliação (MISKOLCI, 2007, p. 112).
} 
O enunciado do docente Nilton nos mostra que por ele já ter um certo conhecimento, uma certa experiência, por já estar na docência por um bom tempo e provavelmente já ter uma vivência acerca das questões de gênero e sexualidade, ele acha que não tem necessidade de abordar mais esses conteúdos nas suas aulas. Porém, essa é uma visão dele; os (as) discentes que estão ali estão em processo de formação e muitos (as) não conseguem fazer as distinções acerca de gênero e sexualidade. Eles (as) precisam amadurecer, para, assim, conseguirem fazer essas distinções - isso é um longo processo, que vai sendo adquirido no decorrer da sua formação. Há docentes que só tiveram uma noção mais "ampla" após ingressarem em cursos de mestrado ou doutorado.

"[...] Eu como professora da instituição [...] eu fui entender, conhecer mais sobre essa discussão de gênero e sexualidade no doutorado. Eu fiz uma disciplina filosofia das diferenças e aí que eu fui compreender essa discussão de gênero e ter um estudo, vamos dizer assim, um aprofundamento maior, de leitura, discussão" (EDNA/discente).

Vê-se que a docente somente aprofundou o seu entendimento sobre a discussão de gênero e sexualidade no doutorado, isso só vem confirmar aquilo que nós falamos sobre os (as) discentes ainda não terem maturidade para fazer algumas diferenciações acerca de gênero e sexualidade. Entendemos que a discussão sobre gênero e sexualidade precisa ganhar forma e força no curso de Pedagogia da UESB, pois sabemos que o debate está sendo feito, mas, pelos discursos apresentados, ele precisa ser ampliado. Em relação a isso, as discentes Ester e Carla entendem que:

"[...] Deveria fazer seminários, rodas de conversas, grupos de pesquisas, entre outras atividades [...] provocar esse debate na universidade toda, enquanto uma sociedade acadêmica, para que as pessoas possam refletir sobre essas temáticas. [...] Seria um lugar de debates, diálogo, embates, de justamente provocar essas questões para contribuir na sociedade e às vezes a gente fica muito entre as paredes acadêmicas. Não, vamos ficar tudo aqui, as pesquisas, tudo aqui na academia e aí não há essa articulação com a sociedade, que seria o papel da universidade, justamente fazer isso, essa articulação e contribuir com a formação dos sujeitos que estão na sociedade" (ESTER/discente).

“[...] Eu posso promover debates, posso promover as rodas de conversa, eu posso promover seminários, eu posso nos eixos temáticos mudar um pouco [...]. Então, a gente ... eu posso convidar outros profissionais já que eu jugo que no теи Campus não tem ou eu posso pedir apoio dos outros Campus também. Eu acho que não é ... eu não vou usar a falta de interesse, mas, eu acho uma falta de articulação de poder promover esses eventos, [...] eu preciso instigar isso aos alunos [...] " (CARLA/discente). 
Fomentar discussões iguais a essas enunciadas pelas discentes em toda a universidade é uma forma de propiciar o conhecimento acerca das discussões de gênero e sexualidade a todas aquelas pessoas que estão em instituições escolares ou não escolares. Isso é uma responsabilidade da universidade, como bem disse a discente Ester. Levar o saber não só a quem está em suas agremiações, dentro dos muros da academia, mas, também, a todos que estão lá fora, tem que existir essa articulação entre universidade-sociedade.

Desta forma, "quando na sociedade qualquer sujeito estiver interessado e discutindo tais questões, poderá se considerar que a universidade estará mais perto de cumprir seu papel" (FERREIRA, 2013, p. 177). Mas, para que isso ocorra é preciso que os cursos de formação docente não restrinjam o debate acerca das relações de gênero e sexualidade apenas em uma disciplina específica, como temos observado nos discursos dos (as) docentes e discentes analisados. Apenas uma disciplina não dará conta da formação de um sujeito, ele precisa estar em constante transformação, vivenciando outros ambientes, participando de eventos, seminários, grupos de pesquisas, iniciação científica e um componente curricular de 60 horas não é suficiente para que se absorva os conhecimentos necessário à sua formação.

É preciso que haja uma discussão ampla, como defende o discente Jaime: “[...] produzir um conhecimento aberto porque a sociedade ela é muito ampla, ela não é feita só de uma hegemonia, ela é heterogênea. Então, a gente tem que discutir, a universidade, a sociedade em um leque maior, bem ampliada, não só um pensamento”, tem que existir toda uma problematização, um envolvimento de todas as áreas do conhecimento, de todos os sujeitos envolvidos direta e indiretamente na formação desses (as) profissionais.

\section{Considerações finais}

A discussão dos temas relacionados a gênero e sexualidade têm esbarrado em algumas dificuldades nos cursos de formação docente em todo o país, como percebemos na maioria dos discursos dos sujeitos investigados. À medida que os assuntos referentes a essas temáticas remeterem exclusivamente a interesses individuais de alguns (mas) docentes e discentes, as questões que permeiam o dia a dia acadêmico relacionadas a esses conteúdos e que não são problematizadas entre os (as) profissionais responsáveis pela formação ficarão em segundo plano.

A universidade tem sido demandada a se posicionar e assumir sua responsabilidade a respeito dessas discussões, especialmente no que se refere a cursos de formação docente, posto que há na educação do país uma relativa escassez desses estudos, além disso, existe uma 
demanda no contexto escolar relacionada à discussão dessas temáticas. Assim, é fundamental que discentes no seu processo formativo, bem como docentes que não tiveram acesso a esses conteúdos, tenham consciência da existência dessa prática, para que possam exercer criticamente sua atividade, em especial no que diz respeito à transformação do cotidiano da escola e ao questionamento das desigualdades de gênero.

O (a) educador (a) é fundamental para abordar as temáticas de gênero e sexualidade na formação de seus (as) educandos (as), caso isso não aconteça, ainda veremos nas instituições práticas que acabam corroborando a prática de preconceitos, estereótipos, discriminação no ambiente formativo e escolar.

\section{REFERÊNCIAS}

BRASIL. LDB 9.394/1996: Lei de Diretrizes e Bases da Educação Nacional. Brasília: Senado Federal, Coordenação de Edições Técnicas, 2017. 58 p.

CASTRO, Roney Polato de. Experiência e constituição de sujeitos docentes: relações de gênero, sexualidades e formação em Pedagogia. 2014. 256f. Tese (Doutorado em Educação) Universidade Federal de Juiz de Fora. Faculdade de Educação. Programa de Pós-Graduação em Educação. Juiz de Fora, 2014.

CIRQUEIRA, Nilson Sousa; SANTANA, José Valdir Jesus de; PEREIRA, Reginaldo Santos. A presença masculina na educação infantil: questões de gênero e docência. In: EUGENIO, Benedito Gonçalves [et al]. Diversidade e educação: múltiplos olhares. Uberlândia: Navegando Publicações, 2018. p. 69-89.

FAZENDA, Ivani (Org.). O que é interdisciplinaridade? São Paulo: Cortez, 2008.

FELIPE, Delton Aparecido; TAKARA, Samilo. Narrativas midiáticas sobre a sexualidade: educação, diferenças e problemáticas à formação docente. Revista Práxis Educacional, Vitória da Conquista, v. 16, n. 39, abr./jun. 2020.Disponível em: <https://periodicos2.uesb.br/index.php/praxis/article/view/6363>. Acesso em: 03 de fevereiro de 2021.

FERREIRA, Taisa de Sousa. Entre o real e o imaginário: problematizando o currículo do curso de Licenciatura em Pedagogia em relação a gênero e sexualidade. Dissertação (Mestrado em Educação) - Universidade Estadual de Feira de Santana. Pró-Reitoria de Pesquisa e Ensino de Pós-Graduação. Departamento de Educação Programa de PósGraduação em Educação. Feira de Santana-BA, 319f. 2013.

FOUCAULT, Michel. Microfísica do poder. Rio de Janeiro: Graal, 1996.

FOUCAULT, Michel. A arqueologia do saber. Rio de Janeiro: Forense, 1986. 
FURLANI, Jimena. Políticas identitárias na educação sexual. In: GROSSI, Miriam Pillar [et al]. Movimentos sociais, educação e sexualidades. Rio de Janeiro: Garamond, 2005.

GORE, Jennifer M. Foucault e educação: fascinantes desafios. In: SILVA, Tomaz Tadeu da. (Org.). O sujeito da educação: estudos foucaultianos. Petrópolis: Vozes, 2010. p. 09-20.

HAMPEL, Alissandra. “A gente não pensava nisso...": educação para a sexualidade, gênero e formação docente na região da Campanha/RS. 2013. 302f. Tese (Doutorado em Educação) - Universidade Federal do Rio Grande do Sul. Faculdade de Educação. Programa de PósGraduação em Educação, Porto Alegre, 2013.

MEYER, Dagmar Estermann. De coisas que aprendi durante o exercício da docência no ensino superior: aportes dos estudos de gênero e culturais e da teorização foucaultiana. In: NASCIMENTO, Ana Cristina; DORNELLES, Priscilla Gomes (Orgs.). Babado acadêmico no recôncavo baiano: universidade, gênero e sexualidade. Salvador: Edufba, 2017. p. 63-78

MEYER, Dagmar Estermann; DORNELLES, Priscila Gomes. Corpo, gênero e sexualidade na escola: cenas contemporâneas, políticas emergentes e teorias potenciais. In: GIVIGI, Ana Cristina Nascimento [et al]. O recôncavo baiano sai do armário: universidade, gênero e sexualidade. Cruz das Almas, BA: UFRB, 2013. p. 31-54.

MISKOLCI, Richard. A teoria queer e a questão das diferenças: por uma analítica da normalização. In: CONGRESSO DE LEITURA DO BRASIL, 16, 2007, Campinas. Anais... Campinas: Unicamp, 2007.

OLIVEIRA, Anna Luiza A. R. Martins de; OLIVEIRA, Gustavo Gilson de. Novas tentativas de controle moral da educação: conflitos sobre gênero e sexualidade no currículo e na formação docente. Educação Unisinos, v. 22, n. 1, jan./mar., 2018b.

OLIVEIRA, João Ferreira, MAUÉS, Oligaíses Cabral. A formação docente no Brasil: Cenários de mudança, políticas e processos em debate. In: OLIVEIRA, Dalila Andrade; VIEIRA, Lívia Fraga. Trabalho na educação básica: A condição docente em sete estados brasileiros. Belo Horizonte, Tino Traço, 2012. p. 63-89.

PARAÍSO, Marlucy Alves. Currículo, gênero e heterotopias em tempos do slogan "ideologia de gênero". In: LOPES, Alice Casimiro; Oliveira, Anna Luiza A.R. Martins de; OLIVEIRA, Gustavo Sousa de (Orgs.). Os gêneros da escola: e o (im) possível silenciamento da diferença no currículo. Recife: Ed. UFPE, 2018. p. 211-241.

REIS, Greissy Leoncio. O gênero e à docência: uma análise de questões de gênero na formação de professores do Instituto de Educação Euclides Dantas. Dissertação (Mestrado em Filosofia e Ciências Humanas) - Universidade Federal da Bahia. Faculdade de Filosofia e Ciências Humanas. Programa de Pós-Graduação em Estudos Interdisciplinares sobre Mulheres, Gênero e Feminismo. Salvador, 194f. 2011.

SALES, Gleiton Silva de. Representações de gênero: um estudo de caso no curso de pedagogia do Campus XIII (Itaberaba-BA), da Universidade do Estado da Bahia. Dissertação (Mestrado em Educação e Contemporaneidade) - Universidade do Estado da Bahia Departamento de Educação - DEDC/Campus I Programa de Pós-Graduação em Educação e Contemporaneidade, Salvador, 261f. 2016. 
SANTOMÉ, Jurjo Torres. Globalização e interdisciplinaridade: o currículo integrado. Porto Alegre: Artes Médicas, 1998.

SILVA, Neiva Maria Rodrigues. Relações de gênero e sexualidades na formação docente: (des) construção de saberes das graduandas do curso de Pedagogia. 2017. 100f. Dissertação (Mestrado profissional) - Universidade Federal de Lavras. Lavras-Minas Gerais, 2017.

SILVA, Tomaz Tadeu da. Alienígenas na sala de aula. 11 ed. Petrópolis - RJ: Vozes, 2013.

SOUZA, Simone Brandão; MIRANDA, Valéria dos Santos Noronha. Homofobia e invisibilidades na educação. In: GIVIGI, Ana Cristina Nascimento [et al]. O recôncavo baiano sai do armário: universidade, gênero e sexualidade. Cruz das Almas, BA: UFRB, 2013. p. 103- 130.

UESB. UNIVERSIDADE ESTADUAL DO SUDOESTE DA BAHIA. Currículo do curso de Licenciatura em Pedagogia. Itapetinga: UESB, 2010.

WELTER, Tânia; GRAUPE, Marelli Eliane; GROSSI, Miriam Pillar. Homossexualidades e gênero na escola: representações de estudantes e educadoras. In: GROSSI, Miriam Pillar; FERNANDES, Felipe Bruno Martins. (Orgs). A força da "situação" de campo: ensaios sobre antropologia e teoria queer. Florianópolis: Editora da UFSC, 2018. p. 419-434.

\section{SOBRE OS AUTORES:}

\section{Nilson Sousa Cirqueira}

Mestre em Educação pelo Programa de Pós-Graduação em Educação (PPGEd) da Universidade Estadual do Sudoeste da Bahia (UESB), Campus de Vitória da Conquista-Bahia. Graduado em Pedagogia pela UESB. Membro do grupo de pesquisa Infância, Educação e Contemporaneidade. E-mail: nilsonmestradouesb@outlook.com

(iD https://orcid.org/0000-0002-4116-9975

\section{José Valdir Jesus de Santana}

Doutor em Antropologia Social pela Universidade Federal de São Carlos (UFSCar). Professor Titular da Universidade Estadual do Sudoeste da Bahia (UESB). Atua no Programa de PósGraduação em Relações Étnicas e Contemporaneidade e no Programa de Pós-Graduação em Ensino da UESB. Líder do Grupo de Pesquisa em Etnicidades, Relações Raciais e Educação. E-mail: santanavaldao@yahoo.com.br

(iD) https://orcid.org/0000-0001-7215-2562

\section{Reginaldo Santos Pereira}

Doutor em Educação pela Universidade Federal de São Carlos (UFSCar). Professor Adjunto da Universidade Estadual do Sudoeste da Bahia (UESB). Atua no Programa de Pós-graduação em Educação (PPGEd) da UESB. Líder do Grupo de Pesquisa Infância, Educação e Contemporaneidade. E-mail: reginaldouesb@gmail.com

(iD) https://orcid.org/0000-0001-6169-9773 